\title{
MeTaEducArte (Método para Talleres de Educación desde el Arte). El arte contemporáneo como medio de expresión en la Educación Infantil y Primaria con uso de TIC
}

\author{
Cristina MORENO PABÓN \\ Universidad Autónoma de Madrid \\ cristina.moreno@uam.es
}

Recibido: 05/10/2012

Aceptado: 23/01/2013

\begin{abstract}
Resumen
El término MeTaEducArte nació en el año 2011 como Proyecto de Innovación Docente, dando nombre y significado al Método para Talleres de Educación desde el Arte contemporáneo, que tiene como principal objetivo que los alumnos y alumnas disfruten, aprendan de forma empática y se comprometan con la educación artística, practicando las técnicas propias del ejercicio del Arte y haciendo uso de las TIC. El proyecto MeTaEducArte, surgió tras una larga experiencia docente-artística, en respuesta a una intensa reflexión sobre la propia práctica educativa, se detectó la necesidad de aplicar diferentes métodos didácticos, en función de las demandas del nuevo tipo de estudiantes que encontramos actualmente en nuestras aulas, en el contexto de la Formación de Profesorado de los estudios de Grado de Infantil y Primaria.
\end{abstract}

Palabras clave: Educación, Metodología, Talleres, Arte Contemporáneo, TIC.

MeTaEducArte (Method of Education Workshops in Art). Contemporary art as a means of expression in Elementary and Primary Education with ICT use

\begin{abstract}
The term MeTaEducArte was born in 2011 as Teaching Innovation Project, giving name and meaning to Method of Education Workshops in Contemporary Art, which main objective is that the students enjoy, learn and engage empathically with art education, practicing the techniques of art practice and using ITC (Information and Communication Technology). The project MeTaEducArte, came after a long teaching experience of Art, in response to intense reflection on the educational practice, identified the need to apply different teaching methods, depending on the demands of the new type of students who are now in our classrooms, in the context of the Teacher Training Degree studies in Elementary and Primary Education.
\end{abstract}

Keywords: Education, Methodology, Workshops, Contemporary Art, ITC.

\section{Referencia normalizada}

MORENO PABÓN, Cristina (2013): "MeTaEducArte (Método para Talleres de Educación desde el Arte). El arte contemporáneo como medio de expresión en la Educación Infantil y Primaria con uso de TIC". Estudios sobre el Mensaje Periodístico. Vol. 19, Núm. especial marzo, págs.: 339-349. Madrid, Servicio de Publicaciones de la Universidad Complutense.

Sumario: 1. Introducción. 2. Metodología: MeTaEducArte; 2.1. Aspectos generales; 2.2. Aspectos competenciales; 2.2.1. Objetivos competenciales; 2.2.2. Objetivos formativos y actitudinales; 2.2.3. Metodología del Aprendizaje; 2.2.4. Objetivos de Docencia; 2.2.5. Evaluación; 2.3. Contenidos y desarrollo de la metodología; 2.3.1. Dinámica de grupo; 2.3.2. El desarrollo del taller; 2.3.3. Autoevaluaciones de lo aprendido, mediante cuestionarios y pregunta; 2.3.4. Conclusiones; 2.3.5. Fase de evaluación del taller. 3. Desarrollo; 3.1. Introducción; 3.2. Algunas dinámicas de grupo usadas; 3.2.1. Dibuja quién es y cómo se siente tu compañero; 3.2.2. Estamos enredados; 3.2.3. La torre más alta y estable. 3.3. Algunos talleres del curso; 3.3.1. Mis sentimientos tienen color: Taller para el aprendizaje de la Teoría del Color; 
3.3.2. Dibuja la música: Tema del dibujo; 3.3.3. ¿Dónde pegamos esto?: Taller de collage; 3.3.4. ¿En qué arenas me muevo?: Taller de escultura de bajo relieve. Añadimos y extraemos material; 3.3.5. Altar mexicano, Taller con distintas técnicas con mucho color (pintura, escultura y papiroflexia); 3.3.6. ¿Qué construyo con lo que me sobra? Escultura con materiales reciclados; 3.3.7. Proyecto "Disfraces y teatro con estilo"; 3.4. Evaluaciones y autoevaluaciones. 4. Conclusiones. 5. Referencias bibliográficas.

\section{Introducción}

Tras una larga experiencia docente-artística y una intensa reflexión sobre la propia práctica educativa, surgió el proyecto MeTaEducArte. Se detectó la necesidad de aplicar distintos métodos didácticos, en función de las demandas del nuevo tipo de alumnado, que encontramos actualmente en nuestras aulas, en el contexto de la Formación de Profesorado de los estudios de Grado de Infantil y Primaria, en la Universidad Autónoma de Madrid. Estos demandan una enseñanza personalizada, activa, atractiva y cercana a su propio lenguaje. Necesitan ver la utilidad y la oportunidad de la aplicación de lo aprendido inmediatamente.

El objetivo de los talleres, es que los estudiantes aprendan, se diviertan y se identifiquen con este tipo de enseñanza. Desde el convencimiento y la experimentación empática, podrán llevar este método e ideología a sus aulas. Educando desde el arte y la emoción ayudarán a sus alumnos a reflexionar sobre su identidad para afianzarla y/o desarrollarla. Se pretende implementar un tipo de formación integral, que incluya conocimientos, experimentación y también el análisis y estudio de los cambios de comportamiento emocional que ocurren mientras aprendemos.

Esta metodología es una combinación de varios métodos de aprendizaje, de los que aporto las referencias bibliográficas en las que me he basado: Aprendizaje Autónomo Motivador (AAM) (Pozo y Monereo, 2009: 9-28); (Pozo y Mateos, 2009: 5969), Aprendizaje Cooperativo (AC) (Cooper et al, 1990); (Johnson et al, 1991), Aprendizaje Basado en Problemas (ABP) (Moreno. y Martínez, 2008) y el método MUPAI (Museo Pedagógico de Arte Infantil) (Belver. y Ullán, 2007: 123-129); (Acaso, 2006).

MeTaEducArte, defiende la necesidad de una "educación artística" alejada del concepto "taller de manualidades", en la enseñanza Infantil y Primaria. Utiliza imágenes visuales que los niños/as y adolescentes podrán identificar, relacionadas con los mensajes visuales que encuentran en su vida diaria. La utilización de las TIC como medio de presentación de estos talleres es fundamental.

Este método es dinámico, divertido y atractivo para el alumnado. Cada alumno, al igual que cada artista, encontrará su propio lenguaje dentro del arte para reflexionar y definir su propia identidad. Esta forma de aprender, estimula el lado más creativo del alumno, ayudándole a ser más autónomo en su aprendizaje y fomentando en él la capacidad de análisis, razonamiento y el espíritu crítico.

\section{Metodología: MeTaEducArte}

\subsection{Aspectos generales}

Repensando lo que quería transmitir con esta combinación metodológica, surgió el término "MeTaEducArte", que da sentido, a este Método para Talleres de Educación desde el Arte. Mi "MeTa" como Educadora Artística, es que mis alumnos desde el 
Arte y sus técnicas, disfruten, aprendan y se comprometan con este tipo de enseñanza.

El principal objetivo de MeTaEducArte, además de los objetivos implícitos en el método, es la educación integral, que incluya conocimientos, experimentación y estudio de los cambios de comportamiento emocional, mientras aprendemos.

Estos talleres pretenden ser herramientas, para los futuros docentes de Educación Infantil y de Primaria. Desde la experimentación empática, podrán llevar esta metodológica e ideología a sus aulas. Este método trabaja la identidad, emociones y sentimientos. Si los alumnos lo integran en su enseñanza, ayudarán a su vez a sus alumnos a encontrar su identidad y desarrollarla.

La metodología usada en el diseño y desarrollo de estos talleres teórico-práctico, está basada en los nuevos métodos de enseñanza, como: AAMC, AC y ABP. Estas metodologías han sido utilizadas en conjunción con el método MUPAI.

El método MUPAI incluye arte contemporáneo y como yo, defiende la "educación artística" y no las manualidades, en la enseñanza artística (Acaso, 2006). Utiliza imágenes visuales que los niños podrán identificar y que pueden encontrar en su entorno, relacionadas con su propio lenguaje visual (Acaso, 2009: 21-47).

MeTaEducArte incluye el arte contemporáneo, como medio de expresión artística para cada alumno-artista. Este método cree en la educación artística y el arte como terapia, considerando el arte y sus formas de expresión, un camino para construir la identidad integral del alumno.

Los talleres teórico-prácticos de arte contemporáneo MeTaEducArte., incorporan como soporte pedagógico, las nuevas tecnologías audiovisuales TIC. Un libro fundamental y de consulta realmente útil, para los temas relacionados con las TIC en la enseñanza, es el de la docente universitaria y artista, Ángeles Saura. En el podemos encontrar gran cantidad de referencias y documentación muy atractiva tanto para el profesorado como para los alumnos (Saura, 2011).

MeTaEducArte fomenta el aprendizaje autónomo, la motivación en el aprendizaje, el trabajo cooperativo en grupo y propone el aprendizaje basado en problemas. Se pretende que el alumno de forma empírica, saque sus propias conclusiones. Esta forma de aprender, estimula el lado más creativo del alumno, ayudándole a ser más autónomo en su aprendizaje y fomentándole la capacidad de análisis, razonamiento y el espíritu crítico.

Los currículum de las asignaturas que imparto para los alumnos de Grado en Educación Infantil y Primaria, han sido adaptados a este tipo de enseñanza, con un currículum postmoderno (Efland et al, 2003). Desde esta perspectiva, van a adquirir los conocimientos y competencias curriculares, sobre el arte, sus aplicaciones, sus técnicas y la forma de enseñarlo. Tendencias educativas como la Educación Artística basada en la Cultura Visual (Efland, 2005), apuestan y reivindican el tema de la identidad como uno de los más importantes a tratar (Belver, 2005). Mediante actividades de diverso tipo, incluidas en estos talleres, se busca que los participantes reflexionen sobre su propia identidad (Freedman, 2006). Con los conocimientos adquiridos, se realizarán obras con distintas técnicas, que les harán sentirse creadores y artistas. 


\subsection{Aspectos competenciales}

\subsubsection{Objetivos competenciales}

- Obtención de conocimientos teóricos-prácticos desde la motivación y la creatividad.

- Conocer los conceptos propios del tema tratado.

- Saber realizar las técnicas propias del tema.

- Adquirir competencias de forma empírica y divertida.

\subsubsection{Objetivos formativos y actitudinales}

Desarrollar la capacidad de:

- Trabajo en equipo.

- Creativa e imaginativa.

- Resolución de problemas.

- Capacidad crítica.

- Expresarse en público y dinamizar un grupo.

- Autoevaluación del propio aprendizaje.

- Realizar una evaluación más justa y crítica.

- Autonomía en el aprendizaje.

\subsubsection{Metodología del Aprendizaje}

Basado en:

- El arte contemporáneo.

- Currículum postmoderno.

- Técnicas y estilos que usan los artistas.

- La educación artística, no en manualidades.

- Utilización de las TIC como medio docente.

- Utilización de imágenes de arte contemporáneo y de la cultura visual de los alumnos.

- Una educación integral de la personalidad (conocimientos-sentimientos).

- La identidad del alumno.

- La cooperación en equipo.

- Iniciado por problemas, preguntas e imágenes, que estimulen intriga y debate.

- Rotación de roles.

- Aprender haciendo a expresarse en público.

- Aprender haciendo a dinamizar un grupo.

- Técnica del puzle para la teoría.

- Aprender a través de errores propios y correcciones.

- Aprender desde la práctica y la solución de problemas o casos planteados (estudios de casos).

- Construcción propia a partir de situaciones / materiales.

- Repetición de lo recibido (hacer trabajos para compartir en clase).

- La autoevaluación de lo aprendido. 


\subsubsection{Objetivos de Docencia}

- Centrada en el aprendiz: El docente facilita, orienta y dinamiza; comparte experiencia, hace de moderador y provoca estimulando al grupo.

- Centrada en el docente: Éste muestra y conduce, pero deja hacer de forma autónoma.

\subsubsection{Evaluación}

- Repetición de lo recibido. Evaluación continúa.

- Resolución de nuevos casos, problemas o prácticas más complejas.

- Autoevaluaciones de lo aprendido mediante cuestionarios y preguntas.

- Evaluación del taller y de sus posibilidades de aplicación.

\subsection{Contenidos y desarrollo de la metodología}

\subsubsection{Dinámica de grupo}

El taller comienza con una dinámica de grupo para romper el hielo, que variará dependiendo del grupo, si es un taller aislado o está dentro de un proyecto o asignatura. Las dinámicas no pueden ser las mismas los primeros días de clase, que en la mitad del curso o al final. Lógicamente los objetivos cambian.

\subsubsection{El desarrollo del taller}

El taller comienza con una diapositiva, con la pregunta que sirve de detonante para el grupo y que les hace reflexionar, entrando en los contenidos del taller. Tras las primeras impresiones y una vez roto el hielo, los alumnos mantendrán una actitud de colaboración, interactuando siempre que lo deseen; de esta forma tenemos garantizado el interés en la parte teórica.

Al estar enfocado para infantil y primaria, se recomienda a los alumnos de Formación del Profesorado, comenzar el taller narrando una micro-historia que "enganche" a los alumnos.

Se utilizará el método interactivo (informativo-demostrativo-práctico), haciendo una breve descripción de los distintos materiales que vamos a usar y cómo utilizarlos. Aquí se puede utilizar el estudio de un caso.

Una vez hecha la demostración, y vista la teoría, se procederá a la parte práctica. Cada alumno hará uno o varias composiciones artísticas, utilizando la técnica objeto del tema. Experimentarán la técnica aprendida de forma libre, reflexionando sobre cuáles son los sentimientos evocados y materializándolo en forma de creación artística.

La práctica termina con una encuesta individual, sobre cómo nos hemos sentido. Mostraremos nuestras obras al grupo y expresaremos las experiencias vividas, compartiéndolas con los compañeros. Aprendemos de los demás.

Una vez aprendida la técnica y con mayor destreza, cada grupo hará un trabajo entre los cuatro miembros que lo integran. Aquí es bueno romper los grupos formales y hacer grupos distintos. Este trabajo fomenta la participación, la comprensión y la compenetración. 


\subsubsection{Autoevaluaciones de lo aprendido, mediante cuestionarios y preguntas} La dinámica de evaluación, debe variar de un taller a otro. El factor sorpresa es importante y resulta más divertido. Utilizaremos preguntas lanzadas al grupo para debatir o directamente a un alumno, cuestionarios, o preguntas cortas escritas.

\subsubsection{Conclusiones}

Al finalizar las prácticas, como conclusión, analizaremos en conjunto los objetivos del taller, los procedimientos empleados, lo que hemos aprendido: conocimientos, habilidades actitudes, etc. Entre todos realizaremos una lista visible para el grupo.

\subsubsection{Fase de evaluación del taller}

Para terminar, se hace una autoevaluación del taller. Es muy importante saber la opinión de cada niño o alumno, sobre lo que ha aprendido, si le ha resultado atractivo y si algo se podría mejorar. Todo esto queda recogido en forma de test, donde se valoran cuatro tipos de datos, relativos al nivel de:

- Satisfacción general con el taller.

- Aprendizaje (estudiantes y profesores).

- Satisfacción respecto a los guías/educadores.

- Satisfacción con la forma de exposición.

\section{Desarrollo}

Aplicación de esta metodología durante un curso académico, en una asignatura para la Educación Artística en Primaria

\subsection{Introducción}

Una de las asignaturas en las que se han aplicado los cambios docentes de este proyecto, es Fundamentos de la Educación Artística en Educación Primaria.

El primer día de clase, para que el grupo se presente y comience a interactuar, se puede iniciar con la dinámica de grupo: "Dibuja quién es y cómo se siente tu compañero" Con esta divertida dinámica, presentamos al compañero que esta nuestro lado, rompiendo el hielo y conociéndonos mejor.

A continuación, se expone el programa del curso; en qué consiste y qué es la metodología MeTaEducArte que se utilizará. Se explican sus bases y fundamentos, para alcanzar los objetivos y competencias formativas del programa docente de la asignatura en cuestión.

La metodología usada, está basada principalmente en talleres, dentro de los cuales se incluyen, estudios de caso y dinámicas de grupo, que amenizan y captan la atención de los alumnos durante las tres horas aproximadamente que dura la clase.

\subsection{Algunas dinámicas de grupo usadas}

En todas las dinámicas utilizadas, los alumnos, reflexionan y exponen los objetivos y resultados de estas. 


\subsubsection{Dibuja quién es y cómo se siente tu compañero}

Hablamos, con el compañero que está a nuestro lado; en un tiempo aproximado de 5 minutos, lo conozco mejor, su nombre, sus gustos, sus estudios, etc...Terminamos haciendo un dibujo con colores poniendo el nombre del compañero, con ilustraciones que lo describan. Usaremos los colores, que más le gustan y le hacen sentir mejor.

El dibujo, se hace en un folio doblado en tres partes. El nombre debe de estar en la parte central. Lo doblamos formando un triángulo, puesto sobre la mesa de forma horizontal, quedando a la vista el nombre, con las imágenes que definen al compañero. ¿Quién mejor que nosotros para presentar a nuestro nuevo amigo? Ahora lo conocemos mejor y él me conoce a mí. Así, nos presentamos al grupo todos. Los nombres quedarán expuestos.

\subsubsection{Estamos enredados}

El dinamizador del grupo lanza un ovillo de lana a cualquier compañero quedándose con el extremo, presentándose con algunos datos fáciles de recordar sobre él. El receptor del ovillo hace lo mismo, se presenta y quedándose con el hilo, lanza nuevamente el ovillo, a otro compañero al azar. Al final, el dinamizador tendrá el ovillo de regreso y estaremos todos "enredados", conociéndonos mejor.

Para deshacer la red, el dinamizador lanza el ovillo al compañero que se lo envió y tiene que presentarlo, contando lo que él nos había dicho con anterioridad. Esto se repite y al final, al terminar la dinámica, tendrá el ovillo nuevamente en sus manos.

Esta dinámica, la podemos utilizar, al principio para presentarnos y al finalizar, para sacar conclusiones de lo que más nos ha gustado del taller y lo que hemos aprendido. En cualquier caso, siempre repetimos nuestros nombres, lo que hace que el grupo se afiance.

\subsubsection{La torre más alta y estable}

Con 15 espaguetis, 4 cáscaras de nuez y un metro de cinta adhesiva, tenemos que construir una torre, en grupos de 4 alumnos, que tenga las características siguientes: tiene que ser la más alta, la más estable y la más creativa.

La evaluación se hará entre todos teniendo encuentra estos tres parámetros. Se da un tiempo limitado de 15 minutos aproximadamente.

\section{3. Algunos talleres del curso}

\subsubsection{Mis sentimientos tienen color: Taller para el aprendizaje de la Teoría del Color}

Además de los objetivos descritos e implícitos en el método de enseñanza, el principal objetivo del taller "Mis sentimientos tienen color", es la experimentación y estudio de los cambios de comportamiento emocional, que el color y sus formas de aplicación tienen sobre la conducta y estado de ánimo en el niño.

\subsubsection{Dibuja la música: Tema del dibujo}

Desde la evocación de la música, estudiamos la teoría del dibujo. Escuchando distintos tipos de música, tienen que dibujar lo que sienten mientras la escuchan. Con este 
taller aprendemos las nociones básicas del dibujo, los trazos, las formas, manchas, composición, etc....

\subsection{3. ¿Dónde pegamos esto?: Taller de collage}

Con la misma metodología de MeTaEducArte, aprendemos la técnica del collage. Cada grupo tendrá dos instrucciones distintas para hacer sus trabajos. Cuando mostremos los trabajos al resto de compañeros, estos tienen que averiguar cuáles eran las instrucciones que tenía cada grupo.

\subsection{4. ¿En qué arenas me muevo?: Taller de escultura de bajo relieve. Añadimos y extraemos material}

En este taller, hacemos dibujos con arena, harina, azúcar o sal. Utilizando distintos materiales, experimentamos diferentes texturas. En este taller, la propuesta es realizar, trabajos en grupo sobre una cartulina oscura. Un miembro del grupo comienza la obra, el siguiente la continúa y la termina el cuarto miembro del grupo. Hacemos fotos al trabajo y lo deshacemos. A continuación se rotan los roles. Al final tendremos 4 obras con distintos materiales.

\subsubsection{Altar mexicano, Taller con distintas técnicas con mucho color (pintura, es- cultura y papiroflexia)}

Este taller, está enfocado al conocimiento de otras culturas y sus distintos puntos de vista, ante un mismo acontecimiento o tema. En este taller en concreto, se afronta la forma tan distinta de entender la muerte que tiene la cultura mexicana.

Aprovechamos las vivencias y obras de artistas mexicanos, para profundizar y ayudar a entender este ritual funerario, contradictoriamente alegre y divertido.

Este taller concluye con un proyecto común: Una exposición artística en la facultad, en la que se haga un altar mexicano, donde mostrar las obras realizadas por los alumnos de forma individual y por grupos con esta temática. La exposición la organizarán y montarán los propios alumnos.

\subsection{6. ¿Qué construyo con lo que me sobra? Escultura con materiales reciclados} El objetivo de este taller, es concienciar a los alumnos sobre la necesidad de reciclar. Se realizará una construcción escultórica o instalación, con materiales totalmente reciclados.

\subsubsection{Proyecto "Disfraces y teatro con estilo"}

Se trabaja por grupos, tanto fuera como dentro del aula. Cada grupo escoge y visita un museo, seleccionando cuatro obras distintas y de diferentes artistas. El grupo prepara un trabajo escrito, enlazando las cuatro obras, buscando similitudes y diferencias entre si. Defenderán su trabajo en el aula, con una exposición oral, apoyada digitalmente con el uso de las TIC. Explicarán la obra escogida, el estilo artístico, el artista que lo desarrolló y la técnica utilizada. También harán un resumen del museo visitado. Cada alumno del grupo, preparará y expondrá una actividad relacionada con la obra escogida y el museo, para realizarla con sus futuros alumnos de primaria. 
Fuera del aula, cada grupo seleccionará una de las cuatro obras analizadas por cada miembro, para hacer una representación teatral relacionada con esta. En la representación se podrán utilizar, marionetas o disfraces. Dedicaremos un último taller para la representación teatral y la reflexión sobre los objetivos y logros de este proyecto.

\subsection{Evaluaciones y autoevaluaciones}

En algunos talleres, trabajaremos con la autoevaluación de los trabajos. Por grupos evaluamos cuatro trabajos de otros compañeros. Los alumnos aprenden a autoevaluarse y a evaluar los trabajos de sus compañeros de forma constructiva. Las evaluaciones se hacen teniendo en cuenta valores cuantitativos y cualitativos. Los mensajes cualitativos, siempre se harán valorando el trabajo hecho e invitando a realizar algunas mejoras. La nota numérica está basada en tres criterios de evaluación: técnica, presentación y creatividad.

Una vez evaluados los trabajos, los pasamos a los compañeros, para que puedan ver su evaluación. Terminamos con un debate sobre los resultados; vemos si estamos de acuerdo o no con nuestra evaluación. Si no estamos de acuerdo con la nota, exponemos la defensa del trabajo a toda la clase y entre todos se decide la calificación.

\section{Conclusiones}

La aplicación del método MeTaEducArte, en el contexto de la Formación de Profesorado de los estudios de Grado de Infantil y Primaria, en la Universidad Autónoma de Madrid., durante dos cursos académicos corrobora que:

- Tanto los talleres, los métodos y dinámica de grupo, programadas para cada asignatura, se han de ir adaptando a las necesidades del grupo, al igual que el temario.

- La experiencia en los primeros días de clase, es que una parte importante del grupo suele ser reacio a esta metodología, por los cambios que implica. Están acostumbrados a obedecer órdenes y a hacer trabajos, con unas directrices muy concretas; no a solucionar los problemas e investigar de forma autónoma, los temas a tratar.

- Cuanto comienzan a familiarizarse con la metodología, con sus dinámicas y talleres, cambian de opinión, involucrándose con la enseñanza. Van tomando confianza en si mismos, sintiéndose capaces de alcanzar los objetivos propuestos.

- El grupo se retroalimenta, disfruta aprendiendo y lo principal es que los alumnos ven con ilusión la posibilidad de llevar este tipo de talleres a sus aulas; de hecho, cuando realizaron prácticas en los colegios, pudieron experimentar con esta metodología.

- Compartiendo los trabajos y las experiencias realizados en la clase con todo el grupo, aprenden diferentes formas de resolver un mismo planteamiento. Cada alumno dentro del mismo tema, utiliza los materiales y las técnicas de forma distinta. Estas exposiciones son muy enriquecedoras para todos, incluyéndome a mí, como docente. Los alumnos quedan sorprendidos de la creatividad que pueden desarrollar, suponiendo un gran estímulo para ellos. 
Todos los objetivos de los que parte este método se cumplieron. Recordamos los principales objetivos:

- Obtención de conocimientos teóricos- prácticos desde la motivación y la creatividad.

- Adquisición de competencias de forma empírica y divertida.

- Aprendizaje basado en la cooperación en equipo.

- Desarrollar la capacidad creativa e imaginativa.

- Desarrollar la capacidad de resolución de problemas.

- Fomentar el espíritu crítico.

- Aprender a expresarse en público y dinamizar un grupo de alumnos.

- Capacidad para la autoevaluación del propio aprendizaje.

- Capacidad para hacer una evaluación más justa y crítica.

- Desarrollar la autonomía en el aprendizaje.

Todos estos puntos nos llevan a una formación integral del alumno, que es el objetivo principal de MeTaEducArte.

Otro tema muy importante a tener en cuenta, es el número de alumnos; es difícil dinamizar un grupo de 60 alumnos o más. Las experiencias con los talleres han sido mucho más interesantes y satisfactorias cuando el grupo se desdobla. Con 28 o 30 alumnos en el aula, las exposiciones en grupo y los trabajos en clase, son más productivos. Los alumnos se centran más en lo que están haciendo y existe una mayor compenetración entre ellos y con el profesor.

\section{Referencias bibliográficas}

ACASO, María (2006): La educación artística no son manualidades. Madrid, Catarata.

ACASO, María (2009): El lenguaje visual. Barcelona, Paidós.

BELVER, Manuel y ULLÁN Ana (2007): La creatividad a través del juego. Salamanca, Amarú.

BELVER, Manuel, ACASO, María. y MERODIO, Isabel (2005): Arte Infantil y Cultura Visual. Madrid, Eneida.

COOPER, James, PRESCOTT, Susan, COOK, Lenora, SMITH, Lyle and MUECK, Randall and CUSEO, Joseph (1990): Cooperative Learning and College Instruction. California. State University Foundation, Long Beach, CA.

EFLAND, Arthur (2005): "Infancia y cultura visual”, en BELVER, Manuel, ACASO, María y MERODIO, Isabel: Arte Infantil y Cultura Visual. Madrid, Eneida, pp. 51-69.

EFLAND, Arthur, FREEDMAN, Kerry y STHUR, Patricia. (2003): La educación en el arte posmoderno. Barcelona, Paidós.

FREEDMAN, Kerry. (2006): Enseñando cultura visual. Barcelona, Octaedro. 
JOHNSON, David; JOHNSON, Roger and SMITH, Karl (1991): Cooperative Learning: Increasing College Faculty Instructional Productivity. Washington. Ashe-Eric Higher Education Report No. 4, George Washington University.

MORENO, Rafael. y MARTÍNEZ, Rafael (2008): El Aprendizaje Basado en Problemas en la Enseñanza Universitaria. Murcia, Universidad Murcia.

POZO, Juan y MATEOS, Mar. (2009): "Aprender a aprender: hacia una gestión autónoma y meta-cognitiva del aprendizaje”, en POZO, Juan y PÉREZ, María Puy: Psicología del aprendizaje universitario: la formación de competencias. Madrid, Morata, pp. 54-69.

POZO, Juan y MONEREO, Carles. (2009): "Introducción: La nueva cultura del aprendizaje universitario ¿o por que cambiar nuestras formas de enseñar y aprender?", en POZO, Juan y PÉREZ, María Puy: Psicología del aprendizaje universitario: la formación de competencias. Madrid, Morata, pp. 9-28.

SAURA PERÉZ, Ángeles (2011): Innovación educativa con TIC en Educación Artística, Plástica y Visual. Líneas de investigación y estudios de casos. Madrid, Mad S.L.

\section{Cristina MORENO PABÓN}

Universidad Autónoma de Madrid

Doctora en Bellas Artes. Máster Universitario en Artes Visuales y Educación

Profesora Facultad del Profesorado. Título de Experto Docente por la UAM

Departamento de Educación Artística, Plástica y Visual

Artista plástica y visual.

cristina.moreno@uam.es 